\title{
IMAGE DAN PRE-IMAGE TRANSLASI PADA GRUP FUZZY INTUITIONISTIK
}

\author{
Dian Pratama \\ dianpratama3789@gmail.com
}

\begin{abstract}
A intuitionistic fuzzy set $A$ in $X$ is set gives a membership function $\mu_{A}$ and a non-membership function (the complement of membership function) $v_{A}$ for each $x \in X$ with the sum worth one. When it's applied in group's theory, it will called intuitionistic fuzzy group with conditions membership function is fuzzy subgroup and non-membership function is anti-fuzzy subgroup. In this research, the operator will be given a fuzzy set is called fuzzy translation operator. This operator is a mapping imposed on membership functions (fuzzy subset) to interval [0,1]. This research will discuss the properties homomorphism of translation on intuitionistic fuzzy groups. These properties is the structure of the image and pre-image homomorphism of translation on intuitionistic fuzzy group. We obtain that image and pre-image of translation on intuitionistic fuzzy (normal) groups is also intuitionistic fuzzy (normal) groups.
\end{abstract}

Keywords: fuzzy group, intuitionistic fuzzy group, translation intuitionistic fuzzy group, image and pre-image.

\begin{abstract}
ABSTRAK. Himpunan fuzzy intuitionistik $A$ dari $X$ adalah himpunan yang ditandai oleh suatu fungsi keanggotaan $\mu_{A}$ dan fungsi non-keanggotaan (komplemen dari fungsi keangotaan) $v_{A}$ untuk setiap $x \in X$ dengan sifat penjumlahan keduanya bernilai kurang dari satu. Apabila himpunan yang digunakan adalah aljabar grup, maka memunculkan grup fuzzy intuitionistik dengan syarat fungsi keanggotaan merupakan subgrup fuzzy dan fungsi non-keanggotaan merupakan anti-subgrup fuzzy. Pada penelitian ini, akan diberikan operator himpunan fuzzy yang dinamakan operator translasi fuzzy. Operator translasi fuzzy merupakan pemetaan yang dikenakan pada fungsi keanggotaan (subset fuzzy) ke selang $[0,1]$. Pembahasan dari penelitian adalah meneliti sifat homomorfisma dari suatu translasi grup fuzzy intuitionistik. Sifat tersebut adalah struktur image dan preimage homomorfisma dari translasi pada grup fuzzy intuitionistik. Hasil yang diperoleh adalah image dan pre-image dari translasi pada intuitionistik grup fuzzy (normal) juga merupakan intuitionistik grup fuzzy (normal).
\end{abstract}

Kata Kunci: grup fuzzy, grup fuzzy intuitionistik, translasi grup fuzzy intuitionistik, image dan pre-image

\section{PENDAHULUAN}

Himpunan fuzzy pertama kali diperkenalkan oleh Zadeh (1965). Himpunan fuzzy adalah suatu himpunan yang setiap anggotannya memiliki derajat keanggotaan. Derajat keanggotaan dari himpunan fuzzy dinamakan fungsi keangotaan yang mempunyai nilai pada interval $[0,1]$. Oleh karena itu, sebarang 
himpunan fuzzy $A$ di dalam $X$ dapat direpresentasikan sebagai fungsi dari $X$ ke bilangan riil pada interval $[0,1]$ dan dinamakan subset fuzzy. Rosenfeld (1971) memperkenalkan konsep grup fuzzy yang merupakan penerapan himpunan fuzzy pada aljabar grup. Pada grup fuzzy diperoleh bahwa fungsi keanggotaannya dinamakan subgrup fuzzy. Hal ini terus diteliti oleh Biswas (1986) yang akhirnya memunculkan anti-subgrup fuzzy. Penelitian mengenai subgrup fuzzy dan antisubgrup fuzzy dilakukan antara lain oleh Jeyaraman dan Sheik Abdullah (2010) yang mengkaji homomorfisma dan anti-homomorfisma pada subgrup fuzzy maupun anti-subgrup fuzzy. Hal ini terus diperdalam, salah satunya dengan meneliti hubungan antara fungsi keanggotaan dengan subgrup fuzzy dan fungsi non-keanggotaan dengan anti-subgrup fuzzy. Diberikan sebarang anggota himpunan fuzzy, selain terdapat derajat keanggotaan (fungsi keanggotaan) maka terdapat pula derajat non-keanggotaan (fungsi non-keanggotaan) yang apabila keduannya dijumlahkan bernilaisatu.

Pada penerapannya sehari-hari, terdapat kejadian penjumlahan dari fungsi keanggotaan dan fungsi non-keanggotaan tidak bernilai satu. Misalkan dalam teori probabilitas pada kejadian pemilihan kepala negara. Suatu negara terdapat 2 calon kepala negara $(A$ dan $B$ ). Didefinisikan bahwa probabilitas calon $A$ adalah fungsi keanggotaan dan probabilitas bukan calon $A$ (calon $B$ ) adalah fungsi nonkeanggotaan. Setelah dilakukan pemilihan suara, terdapat pemilih yang tidak menggunakan hakpilih (golput) dan terdapat pula beberapa suara yang tidak sah. Hal ini mengakibatkan penjumlahan probabilitas kedua calon tidak bernilai satu. Kejadian tersebut melatarbelakangi struktur himpunan fuzzy baru dinamakan himpunan fuzzy intuitionistik. Atanassov (1986) mendefinisikan himpunan fuzzy intuitionistik adalah suatu himpunan dengan sifat penjumlahan dari fungsi keanggotaan dan fungsi non-keanggotaan untuk tiap-tiap anggota bernilai kurang dari sama dengan satu. Sharma (2011) membawa konsep tersebut kedalam aljabar grup, sehingga memunculkan grup fuzzy intuitionistik dengan fungsi keanggotaan merupakan subgrup fuzzy dan fungsi non-keanggotaan merupakan anti-subgrup fuzzy. 
Pada lain pihak, dalam teori himpunan terdapat istilah pemetaan (fungsi) yang merupakan aturan pengaitan antara setiap anggota domain ke tepat satu anggota kodomain. Apabila aturan tersebut dikenakan pada himpunan fuzzy dengan domain adalah nilai dari fungsi keanggotaan dan kodomain adalah interval $[0,1]$, maka pemetaan tersebut dinamakan operator fuzzy dan salah satu bentuk operator fuzzy adalah translasi. Souriar (1993) menggunakan operator translasi fuzzy pada himpunan fuzzy dan grup fuzzy. Berdasarkan fenomena yang telah dipaparkan, penelitian ini akan mengkaji sifat-sifat image dan pre-image pada translasi grup fuzzy intuitionistik. Selanjutnya akan dibuktikan pula struktur dari image dan pre-image pada translasi grup fuzzy intuitionistik.

\section{METODE PENELITIAN}

Metode yang dilakukan dalam penelitian ini adalah studi literatur buku dan jurnal ilmiah terutama yang berhubungan dengan himpunan fuzzy intuitionistik, grup fuzzy intuitionistik, dan translasi fuzzy. Langkah-langkah yang digunakan dalam penelitian yaitu :

1) Mendefinisikan grup fuzzy intuitionistik dengan memperumun definisi grup fuzzy.

2) Mendefinisikan translasi pada grup fuzzy intuitionistik sebagai operator.

3) Membuktikan sifat-sifat image dan pre-image pada translasi grup fuzzy intuitionistik.

4) Membuktikan struktur himpunan dari image dan pre-image pada translasi grup fuzzy intuitionistic

\section{HASIL DAN PEMBAHASAN}

\subsection{Himpunan Fuzzy Intuitionistik}

Pada konsep himpunan fuzzy, fungsi $\mu$ merupakan representasi dari fungsi keanggotaan sehingga secara tidak langsung terdapat pula fungsi non-keanggotaan yaitu $v\left(\mu^{c}\right)$ yang dalam hal ini jelas bahwa $\mu+v=1$. Jika diketahui $\mu$ merupakan fungsi keanggotaan dan $v$ fungsi non-keanggotaan dengan sifat 
$\mu+v \leq 1$, maka memunculkan suatu konsep baru yang dinamakan himpunan fuzzy intuitionistik.

Definisi 3.1.1 (Atanassov, 1984) Diberikan himpunan tak kosong . Himpunan A disebut himpunan fuzzy intuitionistik didalam $X \quad$ ditulis $A=\left\{\left\langle x, \mu_{A}(x), v_{A}(x)\right\rangle ; x \in X\right\}$ dengan ketentuan $\mu_{A}: X \rightarrow[0,1]$ dan $v_{A}: X \rightarrow$ $[0,1]$ masing-masing sebagai fungsi keanggotaan dan fungsi non-keanggotaan dari $X$ yang memenuhi $0<\mu_{A}(x)+v_{A}(x) \leq 1$ dan dinotasikan $A=\left(\mu_{A}, v_{A}\right)$.

Untuk selanjutnya himpunan fuzzy intuitionistik cukup ditulis sebagai subset fuzzy intuitionistik. Didefinisikan $A=\left\{\left\langle x, \mu_{A}(x), v_{A}(x)\right\rangle ; x \in X\right\}$ dan $B=\left\{\left\langle x, \mu_{B}(x), v_{B}(x)\right\rangle ; x \in X\right\}$ merupakan subset fuzzy intuitionistik dari $X$. Untuk setiap $x \in X$ berlaku :

1. $A \subseteq B$ jika dan hanya jika $\mu_{A}(x) \leq \mu_{B}(x)$ dan $v_{A}(x) \geq v_{B}(x)$.

2. $A=B$ jika dan hanya jika $\mu_{A}(x)=\mu_{B}(x)$ dan $v_{A}(x)=v_{B}(x)$.

3. $A^{C}=\left\{\left\langle x, \mu_{A}^{c}(x), v^{c}{ }_{A}(x)\right\rangle ; x \in X\right\}$ dengan $\mu_{A}^{c}(x)=v_{A}(x) \operatorname{dan} v_{A}^{c}(x)=$ $\mu_{A}(x)$.

4. $A \cap B=\left\{\left\langle x,\left(\mu_{A} \cap \mu_{B}\right),\left(v_{A} \cap v_{B}\right)\right\rangle ; x \in X\right\}$ dengan ketentuan, $\left(\mu_{A} \cap\right.$

$$
\begin{aligned}
& \left.\mu_{B}\right)(x)=\min \left\{\mu_{A}(x), \mu_{B}(x)\right\}=\mu_{A}(x) \wedge \mu_{B}(x) \text { dan }\left(v_{A} \cap v_{B}\right)(x)= \\
& \max \left\{v_{A}(x), v_{B}(x)\right\}=v_{A}(x) \vee v_{B}(x) .
\end{aligned}
$$

5. $A \cup B=\left\{\left\langle x,\left(\mu_{A} \cup \mu_{B}\right),\left(v_{A} \cup v_{B}\right)\right\rangle ; x \in X\right\}$ dengan ketentuan, $\left(\mu_{A} \cup \mu_{B}\right)(x)=$ $\max \left\{\mu_{A}(x), \mu_{B}(x)\right\}=\mu_{A}(x) \vee \mu_{B}(x)$ dan $\left(v_{A} \cup v_{B}\right)(x)=\min \left\{v_{A}(x), v_{B}(x)\right\}=v_{A}(x) \wedge v_{B}(x)$.

6. $C_{\delta, \theta}(A)=\left\{x \in X \mid \mu_{A}(x) \geq \delta, v_{A}(x) \leq \theta\right\}(\forall \delta, \theta \in[0,1])$ dengan $\delta+\theta \leq 1$.

Pada bagian terakhir ini akan dijelaskan mengenai definisi pemetaan pada subset fuzzy intuitionistik sebagai berikut.

Definisi 3.1.2 (Sharma, 2011) Diketahui , $Y \neq \varnothing$, himpunan A dan B subset fuzzy intuitionistik dari $X$ dan $Y$ serta pemetaan $f: X \rightarrow Y$. Image dari A terhadap pemetaan $f$ disimbolkan $f(A)$ didefinisikan sebagai berikut: 


$$
f(A)(y)=\left(\mu_{f(A)}(y), v_{f(A)}(y)\right)
$$

dengan ketentuan,

$$
\begin{aligned}
& \mu_{f(A)}(y)= \begin{cases}\max \left\{\mu_{A}(x)\right\}, & x \in f^{-1}(y) \\
0, & x \notin f^{-1}(y)\end{cases} \\
& v_{f(A)}(y)= \begin{cases}\min \left\{v_{A}(x)\right\}, & x \in f^{-1}(y) \\
1, & x \notin f^{-1}(y)\end{cases}
\end{aligned}
$$

Pre-image dari $B$ disimbolkan $f^{-1}(B)$ didefiniskan sebagai $f^{-1}(B)(x)=$

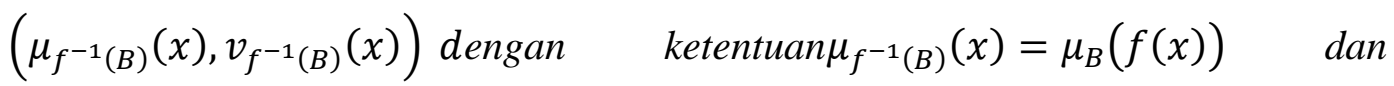
$v_{f^{-1}(B)}(x)=v_{B}(f(x))$ atau $f^{-1}(B)(x)=\left(\mu_{B}(f(x)), v_{B}(f(x))\right)$

Hubungan antara himpunan cut-set dan homomorfisma akan diberikan pada teorema berikut.

Teorema 3.1.3 (Sharma, 2011) Jika $X, Y \neq \varnothing$ dan A,B merupakan subset fuzzy intuitionistik dari $X$ dan $Y$ serta $f: X \rightarrow Y$, maka berlaku sifat-sifat berikut.

1. $f\left(C_{\delta, \theta}(A)\right) \subseteq C_{\delta, \theta}(f(A))$

2. $f^{-1}\left(C_{\delta, \theta}(B)\right)=C_{\delta, \theta}\left(f^{-1}(B)\right)$

\subsection{Grup Fuzzy Intuitionistik}

Pada pembahasan ini akan diberikan beberapa dasar teori menenai struktur intuitionistik pada aljabar grup.

Definisi 3.2.1 (Sharma, 2011) Diberikan grup $G$ dan subset fuzzy intuitionistik A dari G. Himpunan $A=\left(\mu_{A}, v_{A}\right)$ disebut subgrup fuzzy intuitionistik dari $G$ jika dan hanya jika $\quad \mu_{A}\left(x y^{-1}\right) \geq \min \left\{\mu_{A}(x), \mu_{A}(y)\right\} \quad$ dan $v_{A}\left(x y^{-1}\right) \leq \max \left\{\mu_{A}(x), \mu_{A}(y)\right\}$ untuk setiap $x, y \in G$.

Definisi 3.2.2 (Sharma, 2011) Diberikan grup G dan subgrup fuzzy intuitionistik A dari $G$. Himpunan $A=\left(\mu_{A}, v_{A}\right)$ disebut subgrup fuzzy normal intuitionistik dari 
$G$ jika dan hanya jika $\mu_{A}\left(y^{-1} x y\right)=\mu_{A}(x)$ dan $v_{A}\left(y^{-1} x y\right)=v_{A}(x)$ untuk setiap $x, y \in G$.

Selanjutnya diberikan beberapa teorema yang berhubungan dengan cut-set, image dan pre-image pada grup fuzzy intuitionistik.

Teorema 3.2.3 (Sharma, 2011) Diberikan subset fuzzy intuitionistik A dari grup G. Himpunan A merupakan subgrup fuzzy (normal) intuitionistik dari G jika dan hanya jika $C_{\delta, \theta}(A)$ subgrup (normal) dari $G$ untuk setiap $\delta, \theta \in[0,1]$ yang memenuhi $\mu_{A}(e) \geq \delta$ dan $v_{A}(e) \leq \theta$ dan e elemen identitas dari $G$ serta $\delta+\theta \leq 1$.

Teorema 3.2.4 (Sharma,2011) Diberikan homomorfisma grup yang surjektif $f: G_{1} \rightarrow G_{2}$. Jika A merupakan subgrup fuzzy (normal) intuitionistik dari $G_{1}$ maka $f(A)$ merupakan subgrup fuzzy (normal) intuitionistik dari $G_{2}$.

Teorema 3.2.5 (Sharma, 2011) Diberikan homomorfisma grup : $G_{1} \rightarrow G_{2}$. Jika $B$ merupakan subgrup fuzzy (normal) intuitionistik dari $G_{2}$ maka $f^{-1}(B)$ merupakan subgrup fuzzy (normal) intuitionistik dari $G_{1}$.

\subsection{Translasi pada Grup Fuzzy Intuitionistik}

Setelah diberikan definisi grup fuzzy intuitionistik dan operator translasi, selanjutnya akan diberikan definisi operator translasi pada grup fuzzy intuitionistik.

Definisi 3.3.1 (Sharma, 2011) Diberikan himpunan tak kosong $X, \alpha \in[0,1]$ dan $A=\left(\mu_{A}, v_{A}\right)$ subset fuzzy intuitionistik dari X. Operator translasi $A^{\alpha+}=T_{\alpha+}(A)$ dan $A^{\alpha-}=T_{\alpha-}(A)$ didefinisikan sebagai berikut :

$$
\begin{aligned}
& A^{\alpha+}=T_{\alpha+}(A)(x)=\left(\mu_{A^{\alpha+}}(x), v_{A^{\alpha+}}(x)\right) \\
& A^{\alpha-}=T_{\alpha-}(A)(x)=\left(\mu_{A^{\alpha-}}(x), v_{A^{\alpha-}}(x)\right)
\end{aligned}
$$


dengan ketentuan $\mu_{A^{\alpha+}}(x)=\min \left\{\mu_{A}(x)+\alpha, 1\right\}$, dan $v_{A^{\alpha+}}(x)=\max \left\{v_{A}(x)-\right.$ $\alpha, 0\}, \mu_{A^{\alpha-}}(x)=\max \left\{\mu_{A}(x)-\alpha, 0\right\}, \operatorname{dan}_{A^{\alpha-}}(x)=\min \left\{v_{A}(x)+\alpha, 1\right\}$

Apabila diberikan sebarang subgrup fuzzy (normal) intuitionistik $A$ dan $\alpha \in[0,1]$, maka diperoleh bahwa $A^{\alpha+}$ dan $A^{\alpha-}$ juga merupakan subgrup fuzzy (normal) intuitionistik seperti yang dijelaskan berikut.

Teorema 3.3.2 (Sharma, 2011) Jika A subgrup fuzzy (normal) intuitionistik dari grup $G$ maka $A^{\alpha+}$ dan $A^{\alpha-}$ subgrup fuzzy intuitionistik (normal) dari grup $G$ untuk setiap $\alpha \in[0,1]$.

Keadaan dari teorema 3.3.2 tidak berlaku sebaliknya, artinya jika sebarang operator $A^{\alpha+}$ dan $A^{\alpha-}$ merupakan subgrup fuzzy intuitionistik maka belum tentu $A$ merupakan subgrup fuzzy intuitionistik. Berikut ini akan diberikan definisi tambahan tentang himpunan yang mempunyai nilai keanggotaan yang sama dengan elemen identitas pada subgrup fuzzy intuitionistik.

Definisi 3.3.3 (Sharma, 2011) Diberikan grup G dengan elemen identitas e dan A subset fuzzy intuitionistik dari $G$. Didefinisikan himpunan $G_{A}, G_{A^{\alpha+}}, G_{A^{\alpha-}}$ sebagai berikut :

$$
\begin{gathered}
G_{A}=\left\{x \in G \mid \mu_{A}(x)=\mu_{A}(e) \text { dan } v_{A}(x)=\mu_{A}(e)\right\} \\
G_{A^{\alpha+}}=\left\{x \in G \mid \mu_{A^{\alpha+}}(x)=\mu_{A^{\alpha+}}(e) \operatorname{dan}_{A^{\alpha+}}(x)=v_{A^{\alpha+}}(e)\right\} \\
G_{A^{\alpha-}}=\left\{x \in G \mid \mu_{A^{\alpha-}}(x)=\mu_{A^{\alpha-}}(e) \operatorname{dan}_{A^{\alpha-}}(x)=v_{A^{\alpha-}}(e)\right\}
\end{gathered}
$$

Setelah diberikan sifat yang mendukung, maka diperoleh akibat yang merupakan bentuk konvers dari teorema 3.2.2 yang akan diberikan sebagai berikut.

Akibat 3.3.4 Diberikan subset fuzzy intuitionistik A dari grup $G$.

1. Jika $A^{\alpha+}$ subgrup fuzzy (normal) intuitionistik dari $G$ dengan $\alpha<$ $\min \left\{1-p^{\prime \prime}, q^{\prime \prime}\right\}$, maka A subgrup fuzzy (normal) intuitionistik dari G dengan 
ketentuan $p^{\prime \prime}=\max \left\{\mu_{A}(x) ; x \in G-G_{A}\right\}$ dan $q^{\prime \prime}=\min \left\{v_{A}(x) ; x \in G-\right.$ $\left.G_{A}\right\}$.

2. Jika $A^{\alpha-}$ subgrup fuzzy (normal) intuitionistik dari $G$ dengan $\alpha<$ $\min \left\{1-p^{*}, q^{*}\right\}$, maka A subgrup fuzzy (normal) intuitionistik dari $G$ dengan ketentuan $p^{*}=\max \left\{v_{A}(x): x \in G-G_{A}\right\}$ dan $q^{*}=\min \left\{\mu_{A}(x): x \in G-G_{A}\right\}$.

\subsection{Homomorfisma Translasi pada Grup Fuzzy Intuitionistik}

Berikut ini diberikan pembahasan sifat translasi pada grup fuzzy intuitionistik terutama pada bentuk dan struktur image dan pre-image homomorfisma. Pada teorema 3.1.3, apabila bentuk dari $A$ diganti menjadi $A^{\alpha+}$ dan $B$ menjadi $B^{\alpha+}$ untuk setiap $\alpha \in[0,1]$. Hal ini juga berlaku untuk bentuk $A^{\alpha-}$ dan $B^{\alpha-}$ untuk setiap $\alpha \in[0,1]$. Lebih lanjut mengenai sifat translai tersebut akan diberikan definisi himpunan baru yaitu $C_{\delta, \theta}\left(\left(f^{-1}(B)\right)^{\alpha+}\right)$ dan $C_{\delta, \theta}\left(f(A)^{\alpha+}\right)$ sebagai berikut :

$$
\begin{gathered}
C_{\delta, \theta}\left(\left(f^{-1}(B)\right)^{\alpha+}\right)=\left\{x \in G_{1} \mid \mu_{B^{\alpha+}}(f(x)) \geq \delta \text { dan } v_{B^{\alpha+}}(f(x)) \leq \theta\right\} \\
C_{\delta, \theta}\left((f(A))^{\alpha+}\right)=\left\{y \in G_{2} \mid \mu_{f(A)^{\alpha+}}(y) \leq \delta \operatorname{dan} v_{f(A)^{\alpha+}}(y) \leq \theta\right\}
\end{gathered}
$$

Definisi himpunan tersebut juga berlaku untuk $C_{\delta, \theta}\left(\left(f^{-1}(B)\right)^{\alpha-}\right)$ dan $C_{\delta, \theta}\left(f(A)^{\alpha-}\right)$. Pembentukan himpunan baru tersebut memberikan dampak pada teorema 3.1.3 mengenai sifat image dan pre-image dari translasi himpunan fuzzy intuitionistik seperti yang akan diberikan pada teorema berikut,

Teorema 3.4.1 Diberikan sebarang $\alpha \in[0,1]$ dan $f: G_{1} \rightarrow G_{2}$ homomorfisma dari grup $G_{1}$ ke grup $G_{2}$. Jika $B$ subset fuzzy intuitionistik dari $G_{2}$ dan $B^{\alpha+}\left(B^{\alpha-}\right)$ merupakan translasi dari B maka diperoleh,

$$
\begin{gathered}
f^{-1}\left(C_{\delta, \theta}\left(B^{\alpha+}\right)\right)=C_{\delta, \theta}\left(f^{-1}\left(B^{\alpha+}\right)\right)=C_{\delta, \theta}\left(\left(f^{-1}(B)\right)^{\alpha+}\right) \\
f^{-1}\left(C_{\delta, \theta}\left(B^{\alpha-}\right)\right)=C_{\delta, \theta}\left(f^{-1}\left(B^{\alpha-}\right)\right)=C_{\delta, \theta}\left(\left(f^{-1}(B)\right)^{\alpha-}\right)
\end{gathered}
$$

untuk setiap $\delta, \theta \in[0,1]$ dengan $\delta+\theta \leq 1$. 


\section{Bukti:}

Pada Teorema 3.1.3, diperoleh bahwa $f^{-1}\left(C_{\delta, \theta}(B)\right)=C_{\delta, \theta}\left(f^{-1}(B)\right)$ untuk setiap $B$ subset fuzzy intuitionistik di $G_{2}$. Jika himpunan $B$ diganti menjadi $B^{\alpha+}$ maka diperoleh,

$$
f^{-1}\left(C_{\delta, \theta}\left(B^{\alpha+}\right)\right)=C_{\delta, \theta}\left(f^{-1}\left(B^{\alpha+}\right)\right)
$$

Diketahui himpunan $\left(f^{-1}(B)\right)^{\alpha+}=\left(\mu_{T_{\alpha+}\left(f^{-1}(B)\right)}(x), v_{T_{\alpha+}\left(f^{-1}(B)\right)}(x)\right)$ dengan

$$
\begin{aligned}
& \mu_{T_{\alpha+}\left(f^{-1}(B)\right)}(x)=\min \left\{\mu_{f^{-1}(B)}(x)+\alpha, 1\right\}=\mu_{T_{\alpha+}(B)}(f(x)) \\
& v_{T_{\alpha+}\left(f^{-1}(B)\right)}(x)=\max \left\{v_{f^{-1}(B)}(x)-\alpha, 0\right\}=v_{T_{\alpha+}(B)}(f(x))
\end{aligned}
$$

sehingga diperoleh,

$$
\left(f^{-1}(B)\right)^{\alpha+}=\left(\mu_{T_{\alpha+}(B)}(f(x)), v_{T_{\alpha+}(B)}(f(x))\right)=\left(\mu_{B^{\alpha+}}(f(x)), v_{B^{\alpha+}}(f(x))\right)
$$

Selanjutnya akan diberikan definisi $C_{\delta, \theta}\left(\left(f^{-1}(B)\right)^{\alpha+}\right)$ sebagai berikut,

$$
\begin{aligned}
C_{\delta, \theta}\left(\left(f^{-1}(B)\right)^{\alpha+}\right) & =\left\{x \in G_{1} \mid \mu_{B^{\alpha+}}(f(x)) \geq \delta \operatorname{dan} v_{B^{\alpha+}}(f(x)) \leq \theta\right\} \\
& =\left\{x \in f^{-1}(y) \mid \mu_{B^{\alpha+}}(y) \geq \delta \operatorname{dan} v_{B^{\alpha+}}(y) \leq \theta\right\} \\
& =f^{-1}\left(C_{\delta, \theta}\left(B^{\alpha+}\right)\right)
\end{aligned}
$$

Diperoleh $C_{\delta, \theta}\left(\left(f^{-1}(B)\right)^{\alpha+}\right)=f^{-1}\left(C_{\delta, \theta}\left(B^{\alpha+}\right)\right)$

Jadi dari persamaan (1) dan (2) menghasilkan,

$$
C_{\delta, \theta}\left(f^{-1}\left(B^{\alpha+}\right)\right)=C_{\delta, \theta}\left(\left(f^{-1}(B)\right)^{\alpha+}\right)=f^{-1}\left(C_{\delta, \theta}\left(B^{\alpha+}\right)\right)
$$

Pembuktian selanjutnya analog untuk $\left(B^{\alpha-}\right)$.

Teorema 3.4.2 Diberikan sebarang $\alpha \in[0,1]$ dan $f: G_{1} \rightarrow G_{2}$ homomorfisma dari grup $G_{1}$ ke grup $G_{2}$. Jika A subset fuzzy intuitionistik dari $G_{1}$ dan $A^{\alpha+}\left[A^{\alpha-}\right]$ merupakan translasi dari A maka diperoleh,

$$
\begin{gathered}
f\left(C_{\delta, \theta}\left(A^{\alpha+}\right)\right) \subseteq C_{\delta, \theta}\left(f\left(A^{\alpha+}\right)\right) \subseteq C_{\delta, \theta}\left((f(A))^{\alpha+}\right) \\
f\left(C_{\delta, \theta}\left(A^{\alpha-}\right)\right) \subseteq C_{\delta, \theta}\left(f\left(A^{\alpha-}\right)\right) \subseteq C_{\delta, \theta}\left((f(A))^{\alpha-}\right)
\end{gathered}
$$

untuk setiap $\delta, \theta \in[0,1]$ dengan $\delta+\theta \leq 1$. 


\section{Bukti :}

Pada Teorema 3.1.3 diperoleh bahwa, $f\left(C_{\delta, \theta}(A)\right) \subseteq C_{\delta, \theta}(f(A))$ untuk setiap $A$ subset fuzzy intuitionistik di $G_{1}$. Jika himpunan $A$ diganti menjadi $A^{\alpha+}$ maka diperoleh

$$
f\left(C_{\delta, \theta}\left(A^{\alpha+}\right)\right) \subseteq C_{\delta, \theta}\left(f\left(A^{\alpha+}\right)\right) .
$$

Akan ditunjukkan bahwa $C_{\delta, \theta}\left(f\left(A^{\alpha+}\right)\right) \subseteq C_{\delta, \theta}\left((f(A))^{\alpha+}\right)$. Ambil sebarang $y \in C_{\delta, \theta}\left(f\left(A^{\alpha+}\right)\right)$ sehingga, $\mu_{f\left(A^{\alpha+}\right)}(y) \geq \delta$ dan $v_{f\left(A^{\alpha+}\right)}(y) \leq \theta$

$\Leftrightarrow \max \left\{\mu_{A^{\alpha+}}(x): x \in f^{-1}(y)\right\} \geq \delta$ dan $\min \left\{v_{A^{\alpha+}}(x): x \in f^{-1}(y)\right\} \leq \theta$

$\Leftrightarrow \max \left\{\min \left\{\mu_{A}(x)+\alpha, 1\right\}: x \in f^{-1}(y)\right\} \geq \delta$ dan

$\min \left\{\max \left\{v_{A}(x)-\alpha, 0\right\}: x \in f^{-1}(y)\right\} \leq \theta$

$\Leftrightarrow \min \left\{\max \left\{\mu_{A}(x): x \in f^{-1}(y)\right\}+\alpha, 1\right\} \geq \delta$ dan

$\max \left\{\min \left\{v_{A}(x): x \in f^{-1}(y)\right\}-\alpha, 0\right\} \leq \theta$

$\Leftrightarrow \min \left\{\mu_{f(A)}(y)+\alpha, 1\right\} \geq \delta$ dan $\max \left\{v_{f(A)}(y)-\alpha, 0\right\} \leq \theta$

$\Leftrightarrow \mu_{f(A)^{\alpha+}}(y) \geq \delta \operatorname{dan} v_{f(A)^{\alpha+}}(y) \leq \theta$

$\Leftrightarrow y \in C_{\delta, \theta}\left((f(A))^{\alpha+}\right)$.

Jadi dari persamaan (3) dan (4) diperoleh

$$
f\left(C_{\delta, \theta}\left(A^{\alpha+}\right)\right) \subseteq C_{\delta, \theta}\left(f\left(A^{\alpha+}\right)\right) \subseteq C_{\delta, \theta}\left((f(A))^{\alpha+}\right)
$$

Pembuktian selanjutnya analog untuk $\left(A^{\alpha-}\right)$.

Terlihat bahwa pada teorema 3.4.2 hanya diperoleh $f\left(C_{\delta, \theta}\left(A^{\alpha+}\right)\right) \subseteq C_{\delta, \theta}\left(f\left(A^{\alpha+}\right)\right) \subseteq C_{\delta, \theta}\left((f(A))^{\alpha+}\right)$ baik untuk translasi $A^{\alpha+}$ maupun $A^{\alpha-}$. Pada teorema selanjutnya ini akan diberikan syarat cukup agar diperoleh $C_{\delta, \theta}\left((f(A))^{\alpha+}\right) \subseteq C_{\delta, \theta}\left(f\left(A^{\alpha+}\right)\right) \subseteq f\left(C_{\delta, \theta}\left(A^{\alpha+}\right)\right)$.

Teorema 3.4.3 Diberikan sebarang $\alpha \in[0,1]$ dan $f: G_{1} \rightarrow G_{2}$ homomorfisma surjektif dari grup $G_{1}$ ke grup $G_{2}$. Jika A subset fuzzy intuitionistik dari $G_{1}$ dan $A^{\alpha+}\left[A^{\alpha-}\right]$ merupakan translasi dari A maka diperoleh, 


$$
\begin{gathered}
f\left(C_{\delta, \theta}\left(A^{\alpha+}\right)\right)=C_{\delta, \theta}\left(f\left(A^{\alpha+}\right)\right)=C_{\delta, \theta}\left((f(A))^{\alpha+}\right) \\
f\left(C_{\delta, \theta}\left(A^{\alpha-}\right)\right)=C_{\delta, \theta}\left(f\left(A^{\alpha-}\right)\right)=C_{\delta, \theta}\left((f(A))^{\alpha-}\right)
\end{gathered}
$$

untuk setiap $\delta, \theta \in[0,1]$ dengan $\delta+\theta \leq 1$.

\section{Bukti :}

Pada Teorema3.4.2 diperoleh bahwa $C_{\delta, \theta}\left(f\left(A^{\alpha+}\right)\right) \subseteq C_{\delta, \theta}\left((f(A))^{\alpha+}\right)$, tinggal ditunjukkan bahwa $C_{\delta, \theta}\left((f(A))^{\alpha+}\right) \subseteq C_{\delta, \theta}\left(f\left(A^{\alpha+}\right)\right)$. Ambil sebarang $y \in$ $C_{\delta, \theta}\left((f(A))^{\alpha+}\right)$ sehingga diperoleh $\mu_{f(A)^{\alpha+}}(y) \geq \delta$ dan $v_{f(A)^{\alpha+}}(y) \leq \theta$ atau ekuivalen dengan $\min \left\{\mu_{f(A)}(y)+\alpha, 1\right\} \geq \delta$ danmax $\left\{v_{f(A)}(y)-\alpha, 0\right\} \leq \theta$

Karena $f: G_{1} \rightarrow G_{2}$ merupakan homomorfisma surjektif maka terdapat $x \in G_{1}$ sedemikian sehingga, $\mu_{A}(x) \geq \mu_{f(A)}(y)$ dan $v_{A}(x) \leq v_{f(A)}(y)$

$\Leftrightarrow \min \left\{\mu_{A}(x)+\alpha, 1\right\} \geq \min \left\{\mu_{f(A)}(y)+\alpha, 1\right\} \geq \delta$ dan $\max \left\{\mu_{A}(y)+\alpha, 1\right\} \leq \max \left\{v_{f(A)}(y)-\alpha, 0\right\} \leq \theta$

$\Leftrightarrow \min \left\{\mu_{A}(x)+\alpha, 1\right\} \geq \delta$ dan $\max \left\{v_{A}(x)-\alpha, 0\right\} \leq \theta$

$\Leftrightarrow \mu_{A^{\alpha+}}(x) \geq \delta$ dan $v_{A^{\alpha+}}(x) \leq \theta$

$\Leftrightarrow \mu_{A^{\alpha+}}\left(f^{-1}(y)\right) \geq \delta$ dan $v_{A^{\alpha+}}\left(f^{-1}(y)\right) \leq \theta$

$\Leftrightarrow f^{-1}(y) \in C_{\delta, \theta}\left(A^{\alpha+}\right)$

$\Leftrightarrow y \in f\left(C_{\delta, \theta}\left(A^{\alpha+}\right)\right)$

$\Leftrightarrow y \in C_{\delta, \theta}\left(f\left(A^{\alpha+}\right)\right)$

sehingga diperoleh $C_{\delta, \theta}\left(f\left(A^{\alpha+}\right)\right)=C_{\delta, \theta}\left((f(A))^{\alpha+}\right)$. Jadi dapat disimpulkan bahwa

$$
f\left(C_{\delta, \theta}\left(A^{\alpha+}\right)\right)=C_{\delta, \theta}\left(f\left(A^{\alpha+}\right)\right)=C_{\delta, \theta}\left((f(A))^{\alpha+}\right)
$$

Pembuktian selanjutnya analog untuk $\left(A^{\alpha-}\right)$.

Selanjutnya akan diberikan struktur image dan pre-image pada translasi grup fuzzy intuitionistik. 
Teorema 3.4.4 Diberikan homomorfisma surjektif grup $f: G_{1} \rightarrow G_{2}$ dan $\alpha \in$ [0,1]. Jika A merupakan subgrup fuzzy intuitionistik dari $G_{1}$ maka $f\left(A^{\alpha+}\right)\left[f\left(A^{\alpha-}\right)\right]$ merupakan subgrup fuzzy intuitionistik dari $G_{2}$.

\section{Bukti.}

Pembuktian pertama untuk $f\left(A^{\alpha+}\right)$, menurut teorema 3.3.2, jika $A$ subgrup fuzzy intuitionistik maka $A^{\alpha+}$ juga merupakan subgrup fuzzy intuitionistik untuk setiap $\alpha \in[0,1]$. Untuk menunjukan $f\left(A^{\alpha+}\right)$ merupakan intutionistik subgrup fuzzy menurut teorema 3.2.3 cukup membuktikan dengan $C_{\delta, \theta}\left(f\left(A^{\alpha+}\right)\right)$ merupakan subgrup dari $G_{2}$ untuk setiap $\delta, \theta \in[0,1]$ dengan $\delta+\theta \leq 1$. Ambil sebarang $y_{1}, y_{2} \in C_{\delta, \theta}\left(f\left(A^{\alpha+}\right)\right)$ sehingga diperoleh

$$
\mu_{f\left(A^{\alpha+}\right)}\left(y_{1}\right) \geq \delta, v_{f\left(A^{\alpha+}\right)}\left(y_{1}\right) \leq \theta \text { dan } \mu_{f\left(A^{\alpha+}\right)}\left(y_{2}\right) \geq \delta, v_{f\left(A^{\alpha+}\right)}\left(y_{2}\right) \leq \theta
$$

Menurut definisi 3.1.2 mengenai image dan pre-image

$$
\begin{aligned}
& \mu_{f\left(A^{\alpha+}\right)}(y)=\left\{\begin{array}{cc}
\max \left\{\mu_{A^{\alpha+}}(x)\right\}, & x \in f^{-1}(y) \\
0 \quad & x \notin f^{-1}(y)
\end{array}\right. \\
& v_{f\left(A^{\alpha+}\right)}(y)=\left\{\begin{array}{cc}
\min \left\{v_{A^{\alpha+}}(x)\right\}, & x \in f^{-1}(y) \\
1, & x \notin f^{-1}(y)
\end{array}\right.
\end{aligned}
$$

Sehingga terdapat $x_{1}, x_{2} \in G_{1}$ sedemikian sehingga

$$
\begin{array}{r}
\mu_{A^{\alpha+}}\left(x_{1}\right) \geq \mu_{f\left(A^{\alpha+}\right)}\left(y_{1}\right) \geq \delta, v_{A^{\alpha+}}\left(x_{1}\right) \leq v_{f\left(A^{\alpha+}\right)}\left(y_{1}\right) \leq \theta \text { dan } \\
\mu_{A^{\alpha+}}\left(x_{2}\right) \geq \mu_{f\left(A^{\alpha+}\right)}\left(y_{2}\right) \geq \delta, v_{A^{\alpha+}}\left(x_{2}\right) \leq v_{f\left(A^{\alpha+}\right)}\left(y_{2}\right) \leq \theta \\
\Leftrightarrow \mu_{A^{\alpha+}}\left(x_{1}\right) \geq \delta, v_{A^{\alpha+}}\left(x_{1}\right) \geq \theta \text { dan } \mu_{A^{\alpha+}}\left(x_{2}\right) \geq \delta, v_{A^{\alpha+}}\left(x_{2}\right) \geq \theta \\
\Leftrightarrow \min \left\{\mu_{A^{\alpha+}}\left(x_{1}\right), \mu_{A^{\alpha+}}\left(x_{2}\right)\right\} \geq \delta \text { dan } \max \left\{v_{A^{\alpha+}}\left(x_{1}\right), v_{A^{\alpha+}}\left(x_{2}\right)\right\} \leq \theta
\end{array}
$$

Diketahui $A^{\alpha+}$ adalah subgrup fuzzy intuitionistik pada $G_{1}$, sehingga $\mu_{A^{\alpha+}}\left(x_{1} x_{2}^{-1}\right) \geq \min \left\{\mu_{A^{\alpha+}}\left(x_{1}\right), \mu_{A^{\alpha+}}\left(x_{2}\right)\right\} \geq \delta$ dan

$v_{A^{\alpha+}}\left(x_{1} x_{2}^{-1}\right) \leq \max \left\{v_{A^{\alpha+}}\left(x_{1}\right), v_{A^{\alpha+}}\left(x_{2}\right)\right\} \leq \theta$

$\Leftrightarrow \mu_{A^{\alpha+}}\left(x_{1} x_{2}^{-1}\right) \geq \delta, v_{A^{\alpha+}}\left(x_{1} x_{2}^{-1}\right) \leq \theta$

Jadi diperoleh $x_{1} x_{2}^{-1} \in C_{\delta, \theta}\left(A^{\alpha+}\right)$ sehingga $f\left(x_{1} x_{2}^{-1}\right) \in f\left(C_{\delta, \theta}\left(A^{\alpha+}\right)\right) \subseteq$ $C_{\delta, \theta}\left(f\left(A^{\alpha+}\right)\right)$. Karena $f$ homomorfisma diperoleh $f\left(x_{1} x_{2}^{-1}\right)=f\left(x_{1}\right) f\left(x_{2}^{-1}\right) \in$ $C_{\delta, \theta}\left(f\left(A^{\alpha+}\right)\right)$ sehingga $y_{1} y_{2}^{-1} \in C_{\delta, \theta}\left(f\left(A^{\alpha+}\right)\right)$. Jadi $C_{\delta, \theta}\left(f\left(A^{\alpha+}\right)\right)$ merupakan subgrup dari $G_{2}$ sehingga mengakibatkan $f\left(A^{\alpha+}\right)$ merupakan subgrup fuzzy intuitionistik dari $G_{2}$. 
Pembuktian selanjutnya analog untuk $\left(A^{\alpha-}\right)$.

Selanjutnya apabila diketahui $A$ subgrup fuzzy normal intuitionistik, maka $f\left(A^{\alpha+}\right)$ maupun $f\left(A^{\alpha-}\right)$ juga merupakan subgrup fuzzy normal intuitionistik seperti yang akandiberikan pada akibat berikut.

Akibat 3.4.5 Diberikan homomorfisma surjektif grup $f: G_{1} \rightarrow G_{2}$ dan $\alpha \in[0,1]$. Jika A merupakan subgrup fuzzy normal intuitionistik dari $G_{1}$ maka $f\left(A^{\alpha+}\right)\left[f\left(A^{\alpha-}\right)\right]$ merupakan subgrup fuzzy normal intuitionistik dari $G_{2}$.

\section{Bukti.}

Menurut teorema 3.3.2, jika $A$ subgrup fuzzy normal intuitionistik maka $A^{\alpha+}\left[A^{\alpha-}\right]$ juga merupakan subgrup fuzzy normal intuitionistik untuk setiap $\alpha \in[0,1]$. Karena $A^{\alpha+}\left[A^{\alpha-}\right]$ merupakan subgrup fuzzy normal intuitionistik, maka menurut teorema 3.4.4 jelas bahwa $f\left(A^{\alpha+}\right)\left[f\left(A^{\alpha-}\right)\right]$ merupakan subgrup fuzzy normal intuitionistik.

Pada teorema berikutnya akan diberikan pula bahwa pre-image dari translasi subgrup fuzzy intuitionistik merupakan subgrup fuzzy intuitionistik baik untuk $f^{-1}\left(B^{\alpha+}\right)$ maupun $f^{-1}\left(B^{\alpha-}\right)$.

Teorema 3.4.6 Diberikan homomorfisma grup $f: G_{1} \rightarrow G_{2}$ dan $\alpha \in[0,1]$. Jika $B$ merupakan subgrup fuzzy intuitionistik dari $G_{2}$ maka $f^{-1}\left(B^{\alpha+}\right)\left[f^{-1}\left(B^{\alpha-}\right)\right]$ merupakan subgrup fuzzy intuitionistik dari $G_{1}$.

\section{Bukti.}

Pembuktian pertama untuk $f^{-1}\left(B^{\alpha+}\right)$, menurut teorema 3.3.2, jika $B$ subgrup fuzzy intuitionistik maka $B^{\alpha+}$ juga merupakan subgrup fuzzy intuitionistik untuk setiap $\alpha \in[0,1]$. Selanjutnya untuk menunjukan $f^{-1}\left(B^{\alpha+}\right)$ merupakan intutionistik subgrup fuzzy menurut teorema 3.2.3 cukup membuktikan dengan $C_{\delta, \theta}\left(f^{-1}\left(B^{\alpha+}\right)\right)$ merupakan subgrup dari $G_{1}$ untuk setiap $\delta, \theta \in[0,1]$ dengan 
$\delta+\theta \leq 1$. Ambil sebarang $x_{1}, x_{2} \in C_{\delta, \theta}\left(f^{-1}\left(B^{\alpha+}\right)\right)$ sehingga diperoleh $\mu_{f^{-1}\left(B^{\alpha+}\right)}\left(x_{1}\right) \geq \delta, v_{f^{-1}\left(B^{\alpha+}\right)}\left(x_{1}\right) \leq \theta$ dan $\mu_{f^{-1}\left(B^{\alpha+}\right)}\left(x_{2}\right) \geq \delta, v_{f^{-1}\left(B^{\alpha+}\right)}\left(x_{2}\right) \leq \theta$ $\Leftrightarrow \mu_{B^{\alpha+}}\left(f\left(x_{1}\right)\right) \geq \delta, v_{B^{\alpha+}}\left(f\left(x_{1}\right)\right) \leq \theta$ dan $\mu_{B^{\alpha+}}\left(f\left(x_{2}\right)\right) \geq \delta, v_{B^{\alpha+}}\left(f\left(x_{2}\right)\right) \leq \theta$ $\Leftrightarrow \min \left\{\mu_{B^{\alpha+}}\left(f\left(x_{1}\right)\right), \mu_{B^{\alpha+}}\left(f\left(x_{2}\right)\right)\right\} \geq \delta$ dan $\max \left\{v_{B^{\alpha+}}\left(f\left(x_{1}\right)\right), v_{B^{\alpha+}}\left(f\left(x_{2}\right)\right)\right\} \leq$ $\theta$

Diketahui $B^{\alpha+}$ adalah subgrup fuzzy intuitionistik pada $G_{2}$, sehingga

$$
\begin{array}{r}
\mu_{B^{\alpha+}}\left(f\left(x_{1}\right) f\left(x_{2}^{-1}\right)\right) \geq \min \left\{\mu_{B^{\alpha+}}\left(f\left(x_{1}\right)\right), \mu_{B^{\alpha+}}\left(f\left(x_{2}\right)\right)\right\} \geq \delta \text { dan } \\
v_{B^{\alpha+}}\left(f\left(x_{1}\right) f\left(x_{2}^{-1}\right)\right) \leq \max \left\{v_{B^{\alpha+}}\left(f\left(x_{1}\right)\right), v_{B^{\alpha+}}\left(f\left(x_{2}\right)\right)\right\} \leq \theta \\
\Leftrightarrow \mu_{B^{\alpha+}}\left(f\left(x_{1}\right) f\left(x_{2}^{-1}\right)\right) \geq \delta \text { dan } v_{B^{\alpha+}}\left(f\left(x_{1}\right) f\left(x_{2}^{-1}\right)\right) \leq \theta
\end{array}
$$

dengan kata lain $f\left(x_{1}\right) f\left(x_{2}^{-1}\right) \in C_{\delta, \theta}\left(B^{\alpha+}\right)$. Karena $f$ homomorfisma diperoleh $f\left(x_{1} x_{2}^{-1}\right) \in C_{\delta, \theta}\left(B^{\alpha+}\right)$ atau dengan kata lain $x_{1} x_{2}^{-1} \in f^{-1}\left(C_{\delta, \theta}\left(B^{\alpha+}\right)\right)=$ $C_{\delta, \theta}\left(f^{-1}\left(B^{\alpha+}\right)\right)$. Jadi $C_{\delta, \theta}\left(f^{-1}\left(B^{\alpha+}\right)\right)$ merupakan subgrup dari $G_{1}$ sehingga mengakibatkan $f^{-1}\left(B^{\alpha+}\right)$ merupakan subgrup fuzzy intuitionistik dari $G_{1}$. Selanjutnya analog untuk $f^{-1}\left(B^{\alpha-}\right)$ sehingga diperoleh $f^{-1}\left(B^{\alpha-}\right)$ subgrup fuzzy intuitionistik.

Sama halnya dengan sifat image, apabila diketahui $B$ subgrup fuzzy normal intuitionistik, maka $f^{-1}\left(B^{\alpha+}\right)$ maupun $f^{-1}\left(B^{\alpha-}\right)$ juga merupakan subgrup fuzzy normal intuitionistik seperti yang akan diberikan pada akibat berikut.

Akibat 3.4.7 Diberikan homomorfisma grup $f: G_{1} \rightarrow G_{2}$ dan $\alpha \in[0,1]$. Jika $B$ merupakan subgrup fuzzy normal intuitionistik dari $G_{2}$ maka $f^{-1}\left(B^{\alpha+}\right)\left[f^{-1}\left(B^{\alpha-}\right)\right]$ merupakan subgrup fuzzy normal intuitionistik dari $G_{1}$.

\section{Bukti:}

Menurut teorema 3.3.2, jika $B$ subgrup fuzzy normal intuitionistik maka $B^{\alpha+}\left[B^{\alpha-}\right]$ juga merupakan subgrup fuzzy normal intuitionistik untuk setiap $\alpha \in[0,1]$. Karena $B^{\alpha+}\left[B^{\alpha-}\right]$ merupakan subgrup fuzzy normal intuitionistik, maka menurut teorema 3.4.6 jelas bahwa $f^{-1}\left(B^{\alpha+}\right)\left[f^{-1}\left(B^{\alpha-}\right)\right]$ merupakan subgrup fuzzy normal intuitionistik. 


\section{KESIMPULAN DAN SARAN}

Dari penjelasan yang telah diberikan, diperoleh kesimpulan bentuk dan struktur dari image dan pre-image translasi subgrup fuzzy intuitionistik. Diberikan sebarang homomorfisma dari $G_{1}$ ke $G_{2}$ dengan $A$ dan $B$ masing-masing merupakan subset fuzzy intuitionistik untuk $G_{1}$ dan $G_{2}$. Jika $A$ subgrup fuzzy intuitionistik dan $f$ bersifat surjektif, maka image dari translasi subgrup fuzzy intuitionistik $A$ ditulis $f\left(A^{\alpha+}\right)\left[f\left(A^{\alpha-}\right)\right]$ juga merupakan subgrup fuzzy intuitionistik. Begitu pula apabila $B$ subgrup fuzzy intuitionistik dan $f$ tidak perlu surjektif, maka pre-image dari translasi subgrup fuzzy intuitionistik $B$ ditulis $f^{-1}\left(B^{\alpha+}\right)\left[f^{-1}\left(B^{\alpha-}\right)\right]$ merupakan subgrup fuzzy intuitionistik. Hal ini juga berlaku apabila $A$ dan $B$ adalah subgrup fuzzy normal intuitionistik, maka $f\left(A^{\alpha+}\right)\left[f\left(A^{\alpha-}\right)\right]$ dan $f^{-1}\left(B^{\alpha+}\right)\left[f^{-1}\left(B^{\alpha-}\right)\right]$ juga merupakan subgrup fuzzy normal intuitionistik. Pada penelitian ini, operator yang digunakan merupakan operator translasi. Sangat memungkinkan untuk menemukan operator lain selain operator translasi misalkan translasi perbesaran. Untuk lebih lanjut disarankan untuk mengembangkan sifat-sifat tanslasi lain seperti koset, normalizer, dan centralizer.

\section{DAFTAR PUSTAKA}

Atanassov, K. T., Intuitionistic fuzzy sets, Fuzzy Sets and Systems, 20 (1984), 8796.

Biswas, R., Fuzzy Subgroups and Anti Fuzzy Subgroups, Fuzzy Sets and Systems, 35 (1990), 21-124.

Jeyaraman, K. dan Sheik Abdullah., The Homomorphism and AntiHomomorphism of Level Subgroups of Fuzzy Subgroups, Int. Math. Forum 5(46) (2010), 2293-2298.

Rosenfeld, A., Fuzzy Groups, J. Math. Anal. Appl., 35 (1971), .512-517.

Sharma, P.K., $(\alpha, \beta)$ - Cut of Intuitionistic Fuzzy Groups, International Mathematical Forum, 6(53) (2011), 2605-2614.

Sharma, P.K., Intuitionistic Fuzzy Groups, IFRSA International Journal of Data Warehousing and Mining, 1(1) (2011). 
Souriar, S., A Study of Translates of Fuzzy Subgroups, Department of Mathematics and Statistics Cochin University of Science and Technology Cochin, 682 022, Kerala, 1993.

Zadeh, L.A., Fuzzy Sets, Information and Control, 8 (1965), 338-353. 